\title{
FIGHTING CLIMATE CHANGE THROUGH 3D PRINTING
}

\author{
Mehtab Sheikh ${ }^{1}$ and Anubhav Saxena ${ }^{2}$ \\ ${ }^{1}$ Schloar, ${ }^{2}$ Associate Professor \\ Department of CSE, Aanand International Engineering College, Jaipur (Rajasthan) India \\ Email: mehtabskh1998@gmail.com, anubhav.saxena@anandice.ac.in
}

\begin{abstract}
To dive deep into the topic, we should first understand the basics of this paper. What is $3 D$ printing? How would you like to have a machine that could make anything you want it sounds good doesn't it well this is now possible through the magic of 3D printers. While you might not yet see a 3D printer sitting alongside your toaster or your TV at home you will start to see them more and more in places like schools in shops in hospitals and many other places but what is a 3D printer. How does 3D printing allow us to make almost anything from nothing? Every day Darussalam generates more than 400 tons of plastic waste. The plastic finds its way into the ocean and is picked up by waste pickers or burned, but, plastic doesn't disappear overnight instead it takes between 450 and a thousand years for a single bottle to fully decompose so, nature is silently dying. Soon even humankind won't find any clean source of food and water. Enterprise mind in the world to work together understand words in the value by creating new machines that the recycle plastic virtual is a $3 D$ printer filament and to innovate new product post conversion money. It is very useful technology which can helpful in plastic waste management and recycling. This is very useful in protecting our marine and terrestrial ecosystems. It would also a source of livelihood for numerous people.
\end{abstract}

Key words: 3D Printing, Climate Change, Plastic Waste, E-Waste, Additive Manufacturing

\section{Introduction}

The engineers are using 3D printers to make parts of jet engines that are lighter and stronger to make airplanes and more efficient and use less fuel. Doctors are using 3D printers to make new hands and arms and legs that are perfectly fitted for the patients who need them. Even chefs are experimenting to make amazing new types of food that you just couldn't even imagine. Hospitals are using 3D printers to make new body parts for people such as new bones to repair really bad fractures perhaps to the face or the hand. Even using 3D printers to make objects from cartilage the thing that your ear is made of to make new ears for people who may have had a bad accident. One day we may even be able to 3D print new organs inside your body like kidneys or livers using the patient's cells in these printers 3D printing is already changing the way we make stuff and who knows what amazing things that you could make with a 3D printer in the future. 3D printing technology is already changing the way we produce objects from tools and toys to clothing and even body parts. 3D printing is a component of a process referred to as additive manufacturing, where an object is made by adding material layer by layer. Additive manufacturing allows designers to make complex parts for machines, airplanes, and cars at a fraction of the value and time of ordinary means like forging moulding and sculpting. Now, smaller consumer-friendly 3D printers are bringing additive manufacturing to home and businesses.

The first step in 3D printing is to create a blueprint of the object you want to print. You can use modelling software like Blender to make your designs otherwise you can visit websites like Thing verse or Shape ways to seek out objects other users have 3D modelled. Once you have a finished design it's time to send it to the printer. Some printers, like the Maker Bot 
Replicator 2, have removable bioplastic spools in the back of the device almost like a string. When the printer receives the info, it pulls the fabric through a tube, melts it, and deposits it to the plate, where it instantly cools. 3D objected is created through layering where the printer will add one layer of the object at a time until you have a fully formed structure. The most common material utilized in 3D printing is plastic. But the utilization of another material leaves the creation of some pretty amazing products beyond simple tools and toys. 3D printing food is becoming very popular and additive manufacturing has allowed for the creation of some pretty intricate treats. This is a great advancement. In the medical world, doctors are testing biomaterials for regenerative medicine. By using a patient's cells, doctors could 3D print small body parts like ears and noses. Some surgeons have even tested 3D printed organs for transplants. Recently, giant 3D printers in China printed ten houses in just one day. Proving just how cost and time-efficient 3D printing can be.

Well, first we need to take a step back and look at how we normally make stuff there are four ways we make things the first way is called subtractive manufacturing? In subtractive manufacturing, we take a lump of material like wood or metal or stone and we cut away some parts of it to make the thing we want so we remove or subtract just like we do in maths. We remove the material we don't need, this way, we create something and this could be carving a wooden chair from a tree or making a statue from some stone. The second way of making stuff is called forming and here we take a block of material and we apply a force to change its shape object is Wallace and Gromit made by shaping or forming plasticise. The third way we make things are called casting and this is where you take a solid material you make it into a liquid and you pour it into a mild and a nice example of casting the way we make chocolate bunnies and Easter eggs. The fourth way we make stuff and that is called additive manufacturing and this is where we have nothing, to begin with, and you take your material to add it exactly where you want it until you have your final object 3D printing is one type of additive manufacturing and it involves making an object by adding material one tiny layer at a time.

So how do you do that well it all starts by making a drawing of the thing you want on your computer. The computer then makes a special kind of file which it sends to the 3D printer and the 3D printer reads that file and prints the object layer by layer to make the thing you want. Sounds interesting but why would you want to do that 3D printing can help people to make new shapes and new objects that were not previously possible and all sorts of different materials can be used like plastics or metals or food or even living cells that your body is made of. So who uses 3D printers who care about?

\section{Can 3D Printing Change the World?}

We should pay attention to some important facts. The name Adam Smith is not only one of the most famous economists in history but he also witnessed the Industrial Revolution first hand. In his most famous work the Wealth of Nations he talks about the production of pills. When Adam Smith was a child pin were made in craft workshops I mean one person was in charge of doing it all how many pins could he produce well that was about 20 a day. Then came along industrial production suddenly factories hire workers specialized workers for each task you don't have to waste time changing jobs since more and more machines are also being brought in. So Adam Smith recounts how work is divided in the factory one worker stretches the wire and other straightens it third cuts it into equal pieces a fourth makes the tip and so on anyway the task of making a pin happens to take 18 different operations some performed by the same worker in this way Adam Smith highlights how with the Industrial Revolution is possible for ten workers to manufacture about 48,000 pins a day or 4,800 per person instead of 20 . All of this progress in just a few days. We are not just talking about pennies we can apply the same theory to all other products clothes food tools but not only that think about the change in mind-set we are talking 
about it. Before the Industrial Revolution, anyone could set up a pin shot they just needed a forge and some tools the problem the production cost of each pin was very high. The Industrial Revolution meant turning the tables suddenly setting up a factory required a lot of initial investment because you have to buy modern machines hire workers etc. at the advantage well that's being able to produce 48,000 pins in a single day that is the unit cost of each pin is much lower. Even get to a point where it almost costs you the same to produce 50,000 pins as it does 60,000 , however, industrial production does have a disadvantage which is that everything it produces is the same of course at the same time that's also a positive mass production is something that has to finds the mentality of the contemporary era mass culture is the most democratic thing that there is and soda production proved it in the 19th century when soda sparkling water was drunk the same way as Coca Cola is drunk now.

The new Industrial Revolution started in 1988 with a gentleman named Scott Crum. This guy was at his house one day and he said I'm going to make my daughter a toy frock yet a thermal fuse gun that many of us used when we were younger during tech classes but instead of using glue even a mixture of polyethylene wax together and devoted himself to pouring several layers until he had created the frog figure. He didn't finish there he designed an entire system to automate the process this is how the first 3D printer was born. Four years later Scott Crum set up his own Stratasys company which already has more than 600 patterns within the field of 3D printing before we go any further think about the change of mind-set that this entails so far almost all methods making a parser based on what is called subtractive manufacturing fabrication. For example, imagine that we want to make a part from titanium well we need a titanium bar and a milling machine the milling machine gradually smoothest the metal piece until the part is obtained in this way the machine removes all the titanium that we don't need. In other words, there's a lot of metal being discarded 3D printing is the opposite that's why it's called additive fabrication. In this case, we deposit material right where we need it the difference is not only noticeable in cost but also in the design of the piece itself most metal and plastic parts are designed to be manufactured which means that they can contain extra material than is needed for its function but that is necessary for the manufacture of the final product however with 3D printing we can make parts up to 60 percent lighter but just as resistance.

The advancement can be seen like this. The planes lighter parts mean lighter planes that consume less fuel to give you an idea for every kilo of weight that we reduce on a plane we're saving about three thousand dollars a year. Half million 3D printers sold in 2017 on track for 100 million sold in 2030. But the real revolution is not in home printers so let's talk about the big printers but ones that cost tens of thousands of dollars the system is the same as the domestic one put on a massive scale. Suddenly we can make custom airplane parts or medical procedures and we can do this with a lot of precision in other words 3D printing brings together the best of both worlds unique pieces as if made by an artisan but with the precision of the machine. 3D printing applied to MRO of fa-18 Hornet by US Marines we're talking about a United States base in Japan where they' are printing parts to repair an airplane imagine the cost and time savings of making the spare part yourself instead of ordering it from the US production Factory and we're not just talking about planes, for example, think of dentists in Madrid there are already dental clinics that can have your new dental crown tailor-made to your mouth within 24 hours how do they make it so quick well that is because they have their prosthetic lab. There's no middleman they can say goodbye to all logistics costs but we can go even further let's have a look at the textile industry have you ever heard of fast fashion I'm sure you've seen ads on Facebook from brands like a sauce or boohoo. These clothing brands competing with giants like $\mathrm{H} \& \mathrm{M}$ and Zara because they have a different strategy big clothing brand designer type of shirt or dress and make thousands of coffees that's how they keep the unit cost down. The problem is that if you launch a shirt design that doesn't sell all those thousands of copies 
you've made have to be thrown away. However, these new brands bring out a range of designs and very few copies of each they test the product in the market once they've seen which shirts sell the most that is when they produce more copies. In other words, it seems that in the next 10 years the fashion industry could also change and that's all very well but in every revolution, there's going to be losers so what is the biggest problem facing a 3D printing. Pirating Mickey Mouse Airbus is along with Boeing the largest aviation Giants. How easy it would be for Airbus to send the 3D file of the part to be printed at Padilla the Argentine state-owned company that is responsible for the maintenance of Airbus in the region if that were the case EV us might not need to have two logistic centres in Argentina and Brazil.

Plastics even play an important in environmental management. For example in protection of the environment plastic liners are used in landfills to prevent leachate from leaching into the ground. Hence it will prevent soil and ground water contamination. Plastics also play an important part in food safety, hygiene and in the medical field. In waste management plastics may even have advantages over paper in terms of volume for example. Every day Darussalam generates more than 400 tons of plastic waste. The plastic finds its way into the ocean and is picked up by waste pickers or burned, but, plastic doesn't disappear overnight instead it takes between 450 and a thousand years for a single bottle to fully decompose so, nature is silently dying. This waste can be reused to adopt 3D printing technology.

A nascent opportunity to rethink the way we use, or rather reuse, plastic is the growing market for 3D printer filament. Predictions suggest that 3D printing filament market will reach 1.052 million US dollar by 2019. Currently, the cost of one $\mathrm{kg}$. of filament is between 25 US dollar and 40 US dollar. However, in new markets, such as Tanzania, this cost can go up to as much as 60 US dollar or even 80 US dollar, including fees for shipping from China. This creates a barrier for the burgeoning local communities interested in 3D printing to access the necessary supplies (blogs.worldbank.org).

\section{Fighting Climate Change through 3D Printing}

Every day Darussalam generates more than 400 tons of plastic waste. The plastic finds its way into the ocean and it's picked off by waste pickers or burned plastic doesn't disappear overnight instead it takes between 450 and a thousand years for a single bottle to fully decomposed nature is silently dying. Soon even humankind won't find any clean source of food and water. How to fix this mess we've created for ourselves. The first step is to change our perception of trash how can we make value out of our waste. The club is the house open illusion the risk of diet film has empowered some of the best engineers and social enterprise mind in the world to work together understand words in the value by creating new machines that the recycle plastic virtual is a 3D printer filament and to innovate new product post conversion money. Currently, in Tanzania, one kilogram of filament cost forty dollars now thanks to the World Bank plastic for filament can be sourced directly from waste pickers groups and can be sold at low cost internationally by companies like reflow filaments. Today the plastic waste that is collected by pickers even shipped straight to China we need more local enterprises to recycle this waste if we could just have ten percent of Earth plastic waste we could make about a million medical tools.

With support from the World Bank tech portrayed has designed the retreat e-waste 3D printer and Thunderhead filament extruder to create useful products for the local community. The Refad has discovered five feasible product markets which could be traded and sold by young entrepreneurs back into their community. For the farmer we can make drip hydroponic agriculture systems to produce more food with less water on smaller pieces of land for schools low-cost microscope can help students understand microbiology. Can fix the machines that fuel 
small industry that lay rotting in the dust for a lack of an expensive imported gear locally designed jewellery and consumer hacks allow 2D images to take 3D life.

\section{Conclusion}

3D printing technology can be very useful for all sectors. If we can adopt this technology, we can fight against climate change. Our soil fertility will remain fertile, because we will not buried any plastic waste in the soil. It will also stop the contamination of ground water. For Darussalam this technology will be successful. It will also save the money and helpful against climate change. We need more local enterprises to recycle this waste if we could just have ten percent of Earth plastic waste we could make about a million medical tools. For the farmer we can make drip hydroponic agriculture systems to produce more food with less water on smaller pieces of land for schools low-cost microscope can help students understand microbiology. So, we can fight climate change through 3D printing. This will also save our soil fertility and contamination of ground water. Ultimately it will also affect the climate change in positive way.

\section{References}

1. Adam Smith's (1776). Classic "The Wealth of Nations", https://www.econlib.org/library /Smith/ smWN.html

2. The Next Production Revolution Implications for Governments and Business Report (2017).Organisation for Economic Co-operation and Development (OECD), with inputs from the United Nations Conference on Trade and Development (UNCTAD) and the United Nations Industrial Development Organisation (UNIDO)

3. Tim Minshall, Explain What is 3D Pringing Form Cambridge University, https://www.ifm .eng.cam.ac.uk/insights/3D-printing/

4. Gibson I., D. Rosen and B. Stucker (2015). Additive Manufacturing Technologies: 3D Printing, Rapid Prototyping, and Direct Digital Manufacturing, Springer, New York.

5. https://blogs.worldbank.org/digital-development/can-we-shift-waste-value-through-3d printing -tanzania

6. https://unfccc.int/

7. https://www.economist.com/

8. https://www.nitandhra.ac.in/main/

9. https://www.nrel.gov/docs/fy01osti/26222.pdf 